\title{
Republicanismo, derechos humanos y deberes tributarios $^{1}$
}

\author{
Oscar Sarlo \\ Catedrático de Filosofia del \\ Derecho, Facultad de Derecho. \\ Investigador Nivel II en Sistema \\ Nacional de Investigación y \\ Innovación, UDELAR, Uruguay \\ Recebido em 10/02/2012 \\ Aprovado em 5/03/2012
}

\section{Resumen}

El trabajo parte de la base de que los derechos repasan algunas críticas autorizadas a esta tienen costos, o que no pueden haber derechos sin deberes. Esto estaba claro en la moral antigua. La revolución francesa, si bien inaugura triunfalmente el discurso de los derechos (libertad e igualdad) no elude los deberes (fraternidad). Sin embargo, en las declaraciones que pretenden desarrollar la nueva moral política, van dejando de lado los deberes. Se sugiere que al ir imponiéndose la mirada liberal (que prioriza los derechos anteriores al estado), en detrimento de la mirada republicana (que no se olvida de 1 a carga de deberes morales), el discurso sobre la moral política ha ido perdiendo el necesario equilibrio. Se situación, y en especial, se rebate la idea de que hablar de derechos equivale también a hablar de los deberes correlativos, porque tal correlatividad no se da en todos los casos. Al final llama la atención sobre la actual crisis europea, resultado de una desconexión entre derechos y deberes, y el éxito de la República China, basada prioritariamente sobre los deberes, lo cual nos plantea el desafío de encontrar un nuevo equilibrio para los países latinoamericanos.

\section{Palabras-clave}

Derechos humanos. Republicanismo. Liberalismo.

1 Texto baseado en ponencia presentada el 11.11.2011, al Seminario "Ética. Derechos Humanos Y Administración tributaria”, Módulo 2 Los derechos humanos y la Administración Tributaria, en el que también disertaron los Drs. Martín Risso y César Pérez Novaro 


\section{Republicanis, human rights and tributes duties}

\section{Oscar Sarlo}

\section{Abstract}

The work assumes that the rights have costs, or that can not have rights without duties. This was clear in the old morality. The French Revolution, spite triumphantly inangurated the discourse of rights (freedom and equality) does not shirk the duties (fraternity). However, statements that seek to develop the new political morality, dooes not considered the duties of humans rights. It happens that the imposing the liberal view (rights-focused pre-state), en the detriment of the Republican look (that do not forget the burden of moral duties), the discourse on political morality has lost the necessary balance. In this text we review some criticism over this situation, in particular, it challenges the idea that talk of rights is also to discuss the correlative duties, because such correlativity is present in all cases. At the end the text draws attention to the current European crisis which is the result of a disconnection between rights and duties, and it examines the success of the Chinas Republic, based primarily on the duties, which give us a challenge to find a new balance for Latin American countries.
Key words

Humans Rights, Republicanism, Liberalisma. Human rights duties. 


\section{Sumario}

Introducción

1 Modernidad, revolución y positivación de la moral

1.1 Moralidad y derecho

1.2 En el origen fueron los derechos y los deberes

1.3 Las primeras declaraciones y el olvido de la "fraternidad"

1.4 El movimiento declaracionista posterior a la II Guerra Mundial

2 La crítica desde la filosofía política

2.1 Planteamiento

2.2 Crítica posmoderna de G. Lipovetsky

2.3 Críticas desde el republicanismo

3 Crítica teórico-analítica del discurso de los derechos

3.1 Planteo

3.2 La correlatividad entre deberes y derechos morales

4 Crítica desde la dogmática constitucional uruguaya

4.1 Planteamiento

4.2 La estructuración de la parte dogmática de la constitución

4.3 El desarrollo de la dogmática sobre la constitución.

5 Derecho tributario, deberes morales y solidaridad

5.1 Planteamiento

5.2 El derecho tributario como positivación institucional de los deberes de solidaridad

5.3 La presupuestación republicana como clave de una política de derechos sustentable 5.4 Posdata de actualidad: las lecciones de la crisis del mundo desarrollado. 


\section{Introducción}

Convocados por un Seminario sobre "Ética, Derechos Humanos y Administración Tributaria" cualquiera pensaría - y quizás los organizadores también lo hayan pensado- que en él se tratarán cuestiones tales como los derechos de los ciudadanos frente a la administración tributaria, o cómo los derechos humanos limitan la potestad tributaria legislativa o su ejecución por la administración tributaria, o la justificación moral de los poderes tributarios, etc.

Y sin duda que ello sería pertinente, porque todo el discurso de los derechos humanos deviene, en última instancia, en pretensiones contra el Estado. Como dice Cruz Parcero, el objetivo y culminación de la lucha por los derechos es - paradojalmente- que éstos se conviertan en deberes a cargo de alguien. En efecto, el proceso de positivación de los DDHH culmina con la determinación de un sujeto obligado a satisfacerlos. Y en una sociedad liberal, ese sujeto no puede ser otro que el Estado.

Pero, como el Estado no es ningún ente ajeno a la sociedad misma, no es ninguna entelequia, para poder cumplir con esas demandas crecientes de derechos, será preciso que sus deberes hacia ciudadanos provistos de "derechos" o "triunfos" (cfr. Dworkin) se transformen, por otro lado, en derechos del Estado contra ciudadanos sujetos a deberes hacia el Estado.

Estas paradojas, nos muestran aspectos interesantes del discurso de los derechos, que suelen estar fuera del foco de la nueva dogmática de los DDHH. A mi modo de ver, esto genera problemas de comprensión teórica, pero también problemas en la comprensión política de la lucha por los DDHH. Trataré de realizar un pequeño aporte al respecto, a cuenta de desarrollos más extensos que serían necesarios.

En este trabajo parto de tres presupuestos básicos, que son también tres convicciones filosófico-políticas:

$1^{\circ}$ ) los derechos no son gratuitos, sino que siempre tienen costos; ${ }^{2}$ por consiguiente, hablar de derechos, implica lógicamente hablar también de las cargas correspondientes.

$2^{\circ}$ ) cuanto más se multiplique la nómina de derechos humanos - y sus generaciones- menos fuerza tendrán como exigencia; por el contrario, cuanto más fuerza moral o jurídica se les atribuya, más limitada será la lista de derechos que la justifiquen adecuadamente; ${ }^{3}$

2 Tesis defendida entre otros por: FARELL, Martin D. E1 costo de los derechos, en Filosofía del Derecho y Economía, Buenos Aires: La Ley, 2006, pp. 93-107; HOLMES, Stephen; SUNSTEIN, Cass R. El costo de los derechos. Por qué la libertad depende de los impuestos, Buenos Aires: Siglo XXI, 2011.

3 Tesis enunciada en: LAPORTA, Francisco. Sobre el concepto de derechos humanos. En Doxa, Núm. 4, (1987), p. 23. 
$\left.3^{\circ}\right)$ la mejor garantía para los derechos humanos, es un sistema institutional sustentable, democrático y racional. ${ }^{4}$

Por consiguiente, este aporte crítico, creo que lejos de debilitar la causa de los derechos humanos, pretende ser una contribución a su consolidación y sustentabilidad. Una retórica de los derechos humanos desentendida de estas cuestiones fundamentales, me parece la mejor manera de empedrar el camino al infierno.

\section{Modernidad, revolución y positivación de la moral}

\subsection{Moralidad y derecho}

La moralidad refiere a las normas y valores sociales que guían el actuar correcto de las personas y su interacción con el prójimo, las comunidades, y su entorno. En todos estos tipos de interacción hay intereses importantes en juego; reglas y normas para proteger estos valores; deberes implícitos en las funciones y posiciones sociales que pueden fomentar estos valores y promover estas reglas; y virtudes humanas o capacidad que nos permiten actuar en consecuencia. Estos factores morales están normalmente relacionados con creencias y prácticas religiosas, políticas, jurídicas y culturales en general.

De una manera u otra, está claro que la positivación del derecho fue una respuesta ante la insuficiencia de la moralidad tradicional como justificación del orden político. La positivación del derecho, que acompaña a la modernidad, se caracteriza por su convencionalidad, legalidad, formalismo y generalidad, lo cual implica la institucionalización de los procesos de creación y cambio de las normas sociales, y garantiza su efectiva aplicación mediante la amenaza de sanciones coercibles.

Desde esta perspectiva, el derecho (positivo) vendría a ser la positivación de una parte de la moralidad, que las sociedades estiman necesario para sustentarlas, y la justificación moral de los sistemas jurídicos se desplaza ya de cada norma en particular, hacia el orden en su conjunto.

4 Esta tesis no recuerdo ahora haberla visto enunciada de esa manera en la literatura más recibida, aunque bien podría ser sostenida en ella. Personalmente, se me hace evidente -desde experiencias cercanas- y conveniente, ante la miopía juridicista que cabe observar en el discurso de colectivos sociales y políticos -incluída la izquierda- que solo parecen preocupados por lograr la "sanción de derechos" sin advertir que su efectividad depende de complejos procesos vinculados a la transformación de la realidad, cambio de culturas y actitudes, que demandan compromisos y voluntades muy poderosos. Así, mientras nuestro Parlamento proclama generosamente derechos de minorías, discapacitados, de acceso a la información, etc., la realidad se mantiene tercamente al margen de los mismos... 


\subsection{En el origen fueron los derechos y los deberes}

Este proceso de positivación implicó la formalización de un discurso normativo dirigido a los ciudadanos, definiendo su específica posición institucional en cada circunstancia, de manera de volver más segura e indiscutible su situación ante el derecho.

El lema de la Revolución francesa fue "Libertad, igualdad, fraternidad", donde la "fraternidad" aludía a los deberes que emanaban de pertenecer a la sociedad.

De alguna manera, ello tenía sentido porque todo el discurso moral estaba concebido en base a deberes: exigencias de realizar o contribuir al bien común.

\subsection{Las primeras declaraciones y el olvido de la "fraternidad"}

Sin embargo, en el proceso de concreción positiva de los ideales de la revolución, las declaraciones toman una orientación diversa.

Si bien la declaración de los derechos del hombre están inspirados en el derecho natural, y responden por tanto a ideales morales, el discurso de los derechos es capturado por el ideal político del liberalismo, que ha abandonado el sustento de las virtudes como fundamento, y pasa a endiosar el individualismo y la vida privada como ideal supremo. ${ }^{5}$

De ahí que la famosa declaración de 1789 sólo sea de "los derechos del hombre y del ciudadano" estableciendo una fórmula de compromiso, donde al tiempo que reconoce al derecho natural (moral) como fundamento, consagra los derechos de manera formal y neutra, evitando cualquier prescripción al hombre y al ciudadano con respecto a los fines que deben ser perseguidos en la comunidad.

En los debates que precedieron a la segunda declaración, bajo el predominio jacobino, la inclusión o no de los "deberes", fue objeto de encendida polémica en el '93, llegándose a la conclusión que no incluiría una declaración de deberes.

Sin embargo, la idea de declarar los deberes no se abandonó: será el contenido del famoso decreto de Robespierre del "culto al Ser Supremo" del 18 floreal del año II (primavera de 1794), y más tarde aparecerán en la Declaración de Deberes termidoriana del año III (1795).

En el movimiento republicano que sucedió al proceso de la indepen-

5 En todo este punto, seguimos el excelente estudio de: BASABE, Nere "Derechos del Hombre"

y "Deberes del Ciudadano" en la encrucijada: los lenguajes políticos de la Revolución Francesa y el Abad De Mably, en: revista "Historia Constitucional”, n. 12 [2011], págs. 45-98, http:// www.historiaconstitucional.com, accedido el 12-11-2011. 
dencia de las colonias españolas en américa, reaparecerá la idea de los deberes en las constituciones, aunque siempre en un segundo plano.

\subsection{E1 movimiento declaracionista posterior a la II Guerra Mundial}

Luego de la II Guerra Mundial, comienza un imparable proceso de elaboración de declaraciones de Derechos Humanos a nivel internacional y nacional. Tanto esas declaraciones internacionales de Derechos Humanos como el desarrollo dogmático de las mismas está dominado por el discurso de los derechos lo cual ha dado lugar a una auténtica "cultura de los derechos".

Mas allá que algunas declaraciones contengan todavía enunciación de deberes, ${ }^{6} \mathrm{el}$ discurso de los derechos desplazó totalmente el discurso de los deberes humanos. La Declaración Universal de los Derechos Humanos (1948) en su título sólo alude a los "Derechos Humanos" y en su texto se utiliza la expresión "derecho a" en 53 oportunidades, mientras que la expresión "deber" sólo aparece en dos oportunidades. La Convención Americana sobre Derechos Humanos” (1969) sigue la misma línea, ya que que sólo contiene un único artículo destinado a consagrar genéricamente la "Correlación entre Deberes y Derechos". La Convención Europea ni siquiera contiene una norma general referente a los deberes del hombre ni a la relación entre derechos y deberes. ${ }^{7}$

6 Como la Declaración Americana de los Derechos y Deberes del Hombre (1948), que contiene una equilibrada dosis de derechos y deberes. La Declaración Americana de los Derechos y Deberes del Hombre fue aprobada por la IX Conferencia Internacional Americana realizada en Bogotá en 1948, la misma que dispuso la creación de la Organización de Estados Americanos (OEA). Históricamente, fue el primer acuerdo internacional sobre derechos humanos, anticipando la Declaración Universal de los Derechos Humanos, sancionada seis meses después.

7 Cfr. ESPIELL, H. Gros, La Convencion Americana y la Convencion Europea de Derechos. Analisis Comparativo, Santiago: Editorial Jurídica de Chile, 1991, 135. Allí explica Gros que "No es que se negara la existencia de deberes del hombre, sino que el impacto reciente de las teorías nacionalsocialistas o fascistas aconsejaba no incluir nada que pudiera ayudar a sobre-valorar los deberes y, eventualmente, subordinar la existencia o el goce o ejercicio de los derechos al cumplimiento previo de determinados deberes". En igual sentido, Gros Espiell remite a: EISSEN, Marc-Andre, La Convention Europeenne des Droits de l'Homme et les Obligations de l'indívidu: une mise a jour, en Rene Cassin. Amicorum Discipulorumque Liber, III, y "The European Convention on Human Ríghts and the Duties of the Individual", en Acta Scandinavia Juris Gentium, Vol. 32. 1962, Fasc. 3-4. 


\section{La crítica desde la filosofía política}

\subsection{Planteamiento}

Si bien, como bien señala Cruz Parcero luego de "la Segunda Guerra mundial comenzó la proliferación del lenguaje de los derechos, un fenómeno social complejo que ha transformado el lenguaje político, ético y jurídico" ${ }^{8}$ cabría agregar que ese discurso parecería haber sido capturado por el individualismo liberal, que ha logrado identificar la moralidad del derecho con el discurso de los derechos, priorizando esa lectura sesgada.

La preponderancia aplastante del discurso de los derechos no significa que esté exento de críticas ni que tenga resultados satisfactorios. De hecho, ha dado lugar a numerosas críticas desde diversos puntos de vista "adversos" al liberalismo. Distintas corrientes teóricas y filosóficas han criticado esta tendencia, entre las cuales cabe mencionar a filósofos de la posmodernidad, comunitaristas, republicanos y también algunos pertenecientes a corrientes del catolicismo.

A mi juicio, el discurso de los derechos sobredimensiona la visión moral del liberalismo, dejando en un segundo plano el discurso de los deberes, que era tradicional en la moral, y sin el cual no puede entenderse tampoco la positivación del derecho.

\subsection{Crítica posmoderna de G. Lipovetsky.}

La cultura de los derechos ha sido descrita y criticada con toda elocuencia por Lipovetsky, ${ }^{9}$ quien distingue entre ética religiosa, ética secular (o laica) y la ética del posdeber (o posmoralista). Según Lipovetsky- habríamos entrado en lo que denomina "la época del posdeber", en lo cual "reside la excepcional novedad de nuestra cultura ética". Nuestra sociedad, lejos de exaltar las órdenes superiores, las órdenes del deber y de la obligación, los banaliza, les quita crédito y consistencia, disuelve y desautoriza el valor de la renuncia y el sacrificio y se dedica a estimular los deseos inmediatos, la felicidad intimista y materialista, la pura diversión sin más. No parece exagerado afirmar que nuestras sociedades han liquidado los valores sacrificiales, ya se trate de valores ordenados a la "otra vida" o, más bien, de valores con finalidades profanas. Lo que importa y lo que a la gente le preocupa no es el deber, sino el bienestar.

CRUZ PARCERO, Juan Antonio. El lenguaje de los derechos, Madrid: Trotta, 2007, p. 153. LIPOVETSKY, Gilles. El crepúsculo del deber. La ética indolora de los nuevos tiempos democráticos, Barcelona: Anagrama, 5a, 2000. 
Si bien nuestras sociedades "proclaman que la única utopía posible es la moral" ello no implica un "retorno de la moral": "La era del deber rigorista y categórico se ha eclipsado en beneficio de una cultura inédita que prefiere las normas del bienestar a las obligaciones supremas del ideal" que "alienta los derechos subjetivos, pero reniega del deber desgarrador"; "Nos hallamos envueltos en el ciclo posmoderno de las democracias que repudian la retórica del deber austero e integral y consagran los derechos individuales a la autonomía, al deseo, a la felicidad”.

\subsection{Críticas desde el republicanismo.}

Desde tiendas republicanas se ha señalado duramente el olvido liberal de la responsabilidad y los deberes. ${ }^{10}$ Para éstos el "lenguaje de los derechos" es una forma de no hablar de deberes y responsabilidades. Guardando silencio sobre las responsabilidades, dice Mary Ann Glendon, ${ }^{11}$ el liberal parece aceptar los beneficios de vivir en una sociedad con un Estado social y democrático de Derecho, sin aceptar los correspondientes deberes tanto personales como cívicos.

Para otro connotado republicano como Taylor las teorías que afirman la primacía de los derechos niegan la primacía de las obligaciones, las mismas que relacionan al individuo con su sociedad y sus autoridades. Tales obligaciones son vistas, en todo caso, como derivadas, condicionadas, dependientes de nuestro consentimiento o de nuestra posible ventaja. ${ }^{12}$

Según Onora O’Neill, ${ }^{13}$ partir de la perspectiva de las obligaciones, si bien puede presentar la desventaja de no ser algo tan resonante como la apelación a los derechos humanos, tiene la ventaja de requerir más realismo, claridad y honestidad respecto a las responsabilidades, su justificación y su asignación. Es más sencillo construir instituciones sabiendo en qué consiste el contenido de un deber que sabiendo qué derechos hay pero sin especificar el contenido de los deberes.

11 Cf. GLENDON, M.A. Rights Talk. The Impoverishment Of Political Discourses, New York: The Free Press, 1991, p. 14

12 TAYLOR, Ch.. Philosophy and the human sciences, U.S.: Cambridge University Press, 1985, p. 188.

13 O’NEILL, Onora. Towards Justice and Virtue, Cambridge: Cambridge University Press, 1996; Constructions of reason: explorations of Kant's practical philosophy Cambridge: Cambridge University Press, 1989, donde reivindica la filosofía práctica kantiana en la cual la obligación toma prioridad sobre los derechos. 


\subsection{Crítica desde el catolicismo}

El filósofo católico Antonio Maria Baggio ${ }^{14}$ señala que con la revolución francesa, la novedad radica en que por primera vez la fraternidad es presentada como un principio universal de carácter político, ya que la fraternidad existía como idea y como práctica ligada a la vida cristiana. Sin embargo, la fraternidad revolucionaria cambia de sentido, y en todo caso, pierde protagonismo frente a los otros dos componentes del tríptico: la libertad y la igualdad.

No obstante, Biaggio al advertir ese olvido, señala las consecuencias negativas del mismo, y llama la atención sobre como reaparecen las demandas de una nueva fraternidad aquí y allá.

\section{Crítica teórico-analítica del discurso de los derechos}

\subsection{Planteo}

El discurso de los derechos no sólo es moralmente deficitario, sino que además carece de rigor teórico-analítico. En efecto, a despecho del esfuerzo que la teoría contemporánea del derecho ha venido haciendo para elaborar un lenguaje analíticamente riguroso, el discurso de los derechos ha reintroducido un lenguaje farragoso, inconsistente, embelesado con sus efectos retóricos sobre los ciudadanos, pero que resulta difícil de manejar con claridad ${ }^{15}$

\subsection{La correlatividad entre deberes y derechos morales.}

Si admitimos hablar de derechos en el discurso moral, entonces se plantea el problema de la correlatividad entre deberes y derechos y, en su caso, el problema de la prioridad o no de alguno de estos conceptos.

La tesis de la correlatividad afirma que la coexistencia del derecho con la obligación es necesaria y no contingente, que el derecho no puede originarse sin la obligación y que si uno de ellos desaparece, se extingue o se renuncia a él, el otro corre la misma suerte. Esta tesis puede asumir mayor fuerza cuando se dice que la correlación entre derechos y obligaciones es conceptual.

14 BAgGiO, Antonio. "La idea de 'fraternidad' entre dos Revoluciones: París 1789-Haití 1791. Pistas de Investigación para una comprensión de la fraternidad como categoría política”, en: BAGgiO, Antonio M. (comp.) El Principio Olvidado: La Fraternidad. En la Política y el Derecho, Buenos Aires: Ciudad Nueva, 54-57. Biaggio es Profesor de la Facultad de Filosofa de la Pontificia Universidad Gregoriana de Roma.

15 En al análisis de esos déficits seguiremos el planteamiento que realiza CRUZ PARCERO, Juan Antonio. E1 lenguaje de los derechos, Madrid: Trotta, 2007, pp. 59-62. 
Si esta tesis fuera acertada, entonces el problema del uso abusivo de los derechos, no tendría problemas teóricos, porque al hablar de "derechos" se estaría hablando también de "deberes".

Sin embargo, esto es falso. Ya Kelsen había puesto de manifiesto que no todos los deberes se corresponden con derechos, mientras que Lyons señaló ${ }^{16}$ que la correlatividad es falsa tratándose de derechos «activos», es decir, derechos a hacer algo. ${ }^{17}$

Últimamente, la teoría analítica ha vuelto la mirada a Hohfeld, quien a comienzos del siglo XX había señalado con mucha claridad que ciertas posiciones o relaciones que caben en una noción amplia de "tener un derecho" no incluyen un deber correlativo, como en la noción de 'privilegio' -definida por Hohfeld- que no supone la existencia de un deber correlativo. ${ }^{18}$

Onora O'Neill si bien incurre en el unilateralismo opuesto, al priorizar la noción de obligación, confirma estos análisis críticos. Partiendo de la distinción entre las perspectivas del agente (agency) y la del receptor (recipience), que se corresponden, con la del obligado y con la del beneficiario o titular del derecho, sostiene que el lenguaje de los derechos deja muchas obligaciones "colgadas en el vacío" pues no todos los deberes tienen derechos correlativos. ${ }^{19}$

16 LYONS, D., The Correlativity of Rights and Duties: Noüs 4/1 (1979), pp. 45-55.

17 Por ejemplo, el derecho a la libertad de empresa o de profesión no implica que conceptualmente haya alguien obligado, las obligaciones se obtienen a través de concreciones del derecho, pero nada hay conceptualment hablando que me indique que el gobierno, todas las personas y/o ciertos sujetos particulares tengan una obligación correlativa de ese derecho.

18 HOHFELD, W.N. Conceptos jurídicos fundamentales, México: Fontamara, 1991. La vuelta a Hohfeld se había iniciado en la teoría escandinava los trabajos de Simo ZITTING y Alf ROSS (Sobre el concepto y la justicia, 1953). Le siguieron Genaro CARRIÓ al traducir su obra al español (Nota Preliminar, 1968), Lars LINDAHL (Position and change: a study in law and logic, 1977), y más recientemente ALEXY (Teoría de los Derechos Fundamentales, 1986), Matti NIEMI (Hohfeld y el análisis de los Derechos, 1996), CRUZ PARCERO (E1 concepto de derecho subjetivo, 1999), etc.. He recurrido también a la tipología de Hohfeld en un reciente trabajo: O. SARLO, Sobre la noción de responsabilidad en la teoría del derecho y dogmática jurídica, en: Ruptura. Una revista Interdisciplinaria de Análisis Jurídico, Montevideo, 2011, No 1, pp. 41-54. A todos ellos nos remitimos para las argumentaciones que fundamentan el rechazo a la tesis de la correlatividad.

19 Para ello O’Neill distingue tres tipos de deberes: los universales perfectos, los especiales perfectos y los imperfectos. Los deberes universales perfectos se tienen respecto a todos, los especiales perfectos respecto a personas determinadas; ambos tipos de deberes perfectos son correlativos de derechos. Los deberes imperfectos son aquellos que carecen de quienes pueden exigirlos, esto es, no se tienen respecto a todos ni respecto a personas específicas, no son, pues, correlativos de derechos. Por tanto, concluye la autora, existen algunas obligaciones fundamentales respecto de las cuales no corresponden derechos fundamentales. Entonces, si los derechos son tomados como punto de partida del debate ético, entonces las obligaciones imperfectas desaparecerán del panorama porque carecen de derechos correlativos; su fundamentación tendría que remitirse de modo indirecto a algún derecho. Cfr. CRUZ PARCERO, Juan Antonio. El lenguaje de los derechos: Ensayo para una teoría estructural de los derechos. Madrid: Trotta, 2007. 


\section{Crítica desde la Dogmática constitucional Uruguaya}

\subsection{Planteamiento}

El discurso de los derechos no sólo es pasible de las críticas filosófico-políticas y teórico-analíticas señaladas, sino que, en el contexto de nuestro país, cabe cuestionarnos si es pertinente desde una perspectiva dogmática.

En efecto, fruto de la influencia dominante que tienen las doctrinas provenientes de los países desarrollados, o quizás debido a prejuicios ideológicos, no ha reparado en la importancia que tienen los deberes en nuestra constitución, y ello le ha llevado a casi ignorarlos en sus comentarios y doctrinas.

Y conste que, no se trata de que nos parezcan mal los énfasis liberales que contiene el discurso de los derechos provenientes de la doctrina desarrollada, sino que el problema está -como siempre- en la recepción de estas doctrinas, que no toman en cuenta el contexto en el cual son producidas. El caso es que -por ejemplo- en la cultura europea no es tan necesario enfatizar en los deberes sociales, porque son culturas más habituadas a la cooperación, especialmente después de la experiencia traumática de la II Guerra Mundial. El problema está en naciones como las latinoamericanas, que reciben las formulaciones dogmáticas europeas, sin haber construido ciudadanías tan densas como aquéllas.

\subsection{La estructuración de la parte dogmática de la constitución}

En primer lugar, cabe destacar que desde 1934 nuestra constitución especifica algunos deberes de "todos los habitantes" de la República.

Esto se hizo metódicamente, modificando el nombre de la Sección II, que desde entonces se denominará "Derechos, Deberes y Garantías", reaccionando así contra la formulación liberal de $1830^{20}$ y de $1918 .{ }^{21}$ Dentro de la sección se agrega un capítulo II donde se especifican diversos deberes de los habitantes, y en el capítulo III se modifica la cláusula de reserva, que ahora se referirá a "la enumeración de

20 En efecto, en la Constitución de 1830 la Sección II solo hacía referencia a "la Ciudadanía, sus derechos, modos de suspenderse, y de perderse", aludiendo únicamente a los derechos políticos. Los derechos fundamentales aparecen recién hacia el final, como Sección XI como "Disposiciones generales". Los derechos allí enumerados tienen un carácter eminentemente liberales, porque refieren a libertades o derechos negativos, y no hace alusión a deberes.

21 La Constitución de 1918 mantiene la ubicación y naturaleza de la declaración de derechos liberales, agregando únicamente la famosa fórmula del art. 173 (actual art. 72), que sólo refiere a "derechos y garantías", pero agregando ahora "derivados de la forma republicana de gobierno". 
derechos, deberes y garantías hecha por la Constitución” (art. 63).

Es cierto que la incorporación de los deberes se produce en un período de fuerte reacción anti-liberal, alentada por las corrientes totalitarias europeas, que aquí tuvieron sin duda resonancia. Sin embargo, no es menos cierto que la declaración de deberes no fue eliminada en ninguna de las revisiones democráticas que tuvo nuestra Constitución, y - por el contrario- han recibido frecuente aplicación en la legislación y en la jurisprudencia.

Con todo, cabe señalar que nuestras constituciones han omitido explicitar el principal deber de los ciudadanos: el contribuir a las cargas públicas, como sí lo hacen otras constituciones, omisión que convendría salvar en una próxima revisión de la Carta Fundamental.

\subsection{E1 desarrollo de la dogmática sobre la constitución.}

Sobre la elaboración doctrinaria uruguaya cabría hacer dos observaciones fundamentales.

a) En primer lugar, en cuanto a la cuestión filosófica subyacente en la dogmática constitucional uruguaya nunca había tenido un tratamiento demasiado profundo, situación que empieza a cambiar desde 1957. ${ }^{23}$ A partir de allí, se va imponiendo

22 Algunas constituciones americanas: Bolivia 1995: "Toda persona tiene [el deber fundamental] De contribuir, en proporción a su capacidad económica, al sostenimiento de los servicios públicos. (art. 8, lit. d); Chile 1980 (2000): “El servicio militar y demás cargas personales que imponga la ley son obligatorios en los términos y formas que ésta determine" (Art. 22); Colombia 1991: "El ejercicio de los derechos y libertades reconocidos en esta Constitución implica responsabilidades.(...) Son deberes de la persona y del ciudadano: (...) Contribuír al financiamiento de los gastos e inversiones del Estado dentro de conceptos de justicia y equidad” (art. 95); Costa Rica 1949: "Los costarricenses deben observar la Constitución y las leyes, servir a la Patria, defenderla y contribuir para los gastos públicos” (Art. 18); México 2001: "Son obligaciones de los mexicanos (...) Contribuir para los gastos públicos, así de la Federación como del Distrito Federal o del Estado y Municipio en que residan, de la manera proporcional y equitativa que dispongan las leyes (art. 31- IV); Venezuela 1999: Toda persona tiene el deber de coadyuvar a los gastos públicos mediante el pago de impuestos, tasas y contribuciones que establezca la ley (Art. 133). En Europa: España 1978: al consagrar "los derechos y deberes de los ciudadanos" dispone que "Todos contribuirán al sostenimiento de los gastos públicos de acuerdo con su capacidad económica mediante un sistema tributario justo inspirado en los principios de igualdad y progresividad que, en ningún caso, tendrá alcance confiscatorio." (art. 31.1). 
una lectura de la dogmática constitucional que sobredimensiona la "pata" liberal del (actual) artículo 72 (la que hace referencia a los derechos, deberes y garantías "inherentes a la personalidad humana"), relegando casi al olvido la que hace referencia a la "pata" republicana (la que refiere a los que derivarían de la "forma republicana de gobierno"). Ello puede responder a la paulatina imposición de una visión liberal individualista, y la pérdida de los ideales republicanos que la propia constitución manda tener presentes en la misma medida. En otros términos, si la construcción dogmática debe partir de algunos ideales filosóficos, me parece indudable que la constitución manda -al menos desde 1918 con toda claridad- armonizar los ideales liberales ("derechos inherentes a la personalidad humana") con los republicanos ("derivados de la forma republicana de gobierno"). Por consiguiente, la reconstrucción dogmática de nuestros textos constitucionales no puede desvirtuar -al menos sin una justificación sólida- esa directiva.

Es importante destacar que en la década de los '60s del siglo XX hay un resurgimiento del interés por el contraste entre republicanismo y liberalismo en el ámbito de la historia constitucional y política, especialmente en Norteamérica, ${ }^{24}$ pero no sólo. En el contexto europeo se ha desarrollado una reformulación interesante del ideal republicano, ${ }^{25}$ que ha motivado una reflexión local, ${ }^{26}$ que creo puede iluminar una interpretación de nuestra constitución, en clave del republicanismo democrá-

23 Véase al respecto: SARLO, Oscar. Derechos, Deberes y Garantías implícitos en la Constitución Uruguaya. Un análisis de filosofía política y epistemología del derecho, en: VÁZQUEZ, Cristina (comp.). Estudios Jurídicos en Homenaje al Prof. Juan Pablo Cajarville Peluffo, Montevideo: FCU, 2011, pp. 1069-1099.

24 Al respecto, cabe mencionar tres libros claves: BAILYN, Bernard The ldeological Origins of the American Revolution (1967), que arremete contra la visión lockeana de la revolución; el segundo es el de WOOD, Gordon S. The Creation of the American Republic (1969), donde el republicanismo encuentra ya su lugar como principio ideológico central; y, por último, el libro de POCOCK, J. G. A. The Machiavellian Moment (1975), que muestra a la Revolución y la Constitución americanas como el "último acto del libro del Renacimiento cívico" y que las ideas de la tradición del humanismo cívico (mezcla del pensamiento aristotélico y maquiavélico respecto del zoon politikon) proporcionan una clave importante para comprender las paradojas de las tensiones modernas. Sigo aquí la reconstrucción expuesta por RIVERO, Ángel. Republicanismo y neo-republicanismo, en revista ISEGORIA, no 33, (2005) pp. $5 \cdot 17$

25 Sobre el punto, seguimos a: PETTIT, Philip. Republicanismo, Barcelona: Paidós, 1999; de FRANCISCO, Andrés Ciudadanía y democracia: un enfoque republicano, Madrid: Los Libros de la Catarata, 2007; HABERMAS, Jürgen. Facticidad y Validez, Madrid: Trotta, 1998. Una articulación práctica del "estado del arte" en la materia, es la propuesta -hoy muy aceptada- de la Comisión Económica y Social de Asia Pacífico de las Naciones Unidas sobre "buena gobernanza".

26 Para unas interesantes referencias a 'lo republicano’ y sus raíces, en el desarrollo jurídico latinoamericano, ver: GROS ESPIELL, Héctor. El constitucionalismo latinoamericano y la codificación en el siglo XIX, en: Anuario iberoamericano de justicia constitucional, Nº 6, 2002, pags. 143-176. Desde la ciencia política, se está desarrollando un replanteamiento de la temática republicana en la historia uruguaya; al respecto puede verse, entre otros: GALLARDO, Javier. Diálogo en la república, en: Polis. Investigación y Análisis Sociopolítico y Psicosocial, Vol. 1, N. 1, 2005 , pags. 57-89; y Las ideas republicanas en los orígenes de la democracia uruguaya, en: Araucaria: Revista Iberoamericana de filosofía, política y humanidades, $\mathrm{N}^{\circ}$ 9, 2003; AAVV, El giro republicano. Bases conceptuales de déficit democrático de América Latina, Montevideo, Trilce, 2009; CAETANO, Gerardo. La República Batllista, Montevideo: Banda Oriental, 2011. 
tico y la democracia deliberativa, ${ }^{27}$ que concilia adecuadamente los ideales republicanos con las garantías liberales, en la medida - claro está - que su praxis no sea ganada por la demagogia política.

b) En segundo lugar, debe señalarse que - y quizás en razón de lo apuntado precedentemente- la doctrina nacional ha relegado el estudio de los deberes fundamentales en la constitución, ${ }^{28}$ que por su inclusión en la cláusula de reserva (art. 72) que remite a los ideales filosófico-políticos de la constitución, habrían merecido una mayor elaboración para orientar la labor de los jueces. ${ }^{29}$

\section{Derecho tributario, deberes morales y solidaridad}

\subsection{Planteamiento}

La mediación del Estado benefactor o de bienestar, ha contribuido a soslayar el papel de los deberes y la responsabilidad en la construcción y la praxis del discurso moral público, haciéndonos olvidar que todos los derechos tienen costos, esto es, generan cargas para la ciudadanía.

Aún los derechos pasivos (de no interferir) tienen el costo de su vigilancia y garantía, que exigen mantener sistemas de policía y de justicia que garanticen esos derechos.

Con más razón, los derechos positivos (prestaciones sociales) tienen costos explícitos, que no siempre son tenidos en cuenta.

27 Una discusión de la democracia deliberativa al más alto nivel en el contexto rioplatense, en: NINO, Carlos S. La constitución de la democracia deliberativa, Barcelona: Gedisa, 1996.

28 Quizás la excepción más significativa sea el detallado estudio de BIASCO, Emilio. Introducción al estudio de los deberes constitucionales. El principio constitucional de solidaridad (http://www.ccee.edu.uy/ensenian/catderpu/material/deberes $\% 20$ constitucionales.PDF). En dicho estudio, Biasco realiza un pormenorizado estudio de los deberes que emanan de las convenciones internacionales y de la Constitución. Hace notar también el escaso tratamiento del tema en nuestra doctrina, y recuerda, por otra parte, que similar observación había hecho SANTI ROMANO en 1945, quien al acometer el tratamiento de las situaciones jurídicas subjetivas, decía que la de los deberes, es la que ha quedado más en la sombra; confundiéndose -a menudo- con la de obligación o mostrándose como la contracara del derecho subjetivo, Vé. Fragmentos de un diccionario jurídico, p. 89-90. Sin embargo, el análisis de Biasco requeriría mayores aportes desde el punto de vista analítico-teórico y desde la fundamentación filosófico-política.

29 Así lo hemos destacado en: SARLO, Oscar. Derechos, Deberes y Garantías implícitos en la Constitución Uruguaya. Un análisis de filosofía política y epistemología del derecho, en: VÁZQUEZ, Cristina (comp.). Estudios Jurídicos en Homenaje al Prof. Juan Pablo Cajarville Peluffo, Montevideo: FCU, 2011, pp. 1069-1099. 
Luego de este largo rodeo panorámico a través de la historia, la teoría y la filosofía reciente, aterrizaré en nuestro tema - el derecho tributario-, aunque el lector ya habrá advertido -si he sido claro- hacia dónde apunta nuestra exposición.

La moral de los deberes y su necesidad de positivación (institucionalización)

Del mismo modo que la moral de los derechos, la moral de los deberes requiere también del aparato institucional para su concreción. Al respecto me permito citar un precisa explicación de Habermas: ${ }^{30}$

Desde luego, estas razones pragmáticas para las tomas de postura y las acciones morales resultan iluminadoras sólo en la medida que estemos pensando en relaciones interpersonales en pequeñas comunidades solidarias como la familia o el vecindario. Las sociedades complejas no pueden mantenerse unidas solamente por medio de sentimientos que como la simpatía y la confianza se dirigen a una esfera de cercanía. El comportamiento moral ante extraños exige virtudes "artificiales", ante todo la disposición a la justicia.

Ante las cadenas abstractas de acción, a los miembros de los grupos primarios de relación se les escapa del campo de visión la reciprocidad entre prestaciones y recompensas - y con ello las razones pragmáticas para la benevolencia-. Los sentimientos de obligación que salvan la distancia entre extraños no son "racionales para mí" al modo de la lealtad frente a los parientes de cuya reciprocidad me puedo fiar. En la medida que la solidaridad es el envés de la justicia, nada se puede objetar al intento de explicar la génesis de los deberes morales a partir de la ampliación de las lealtades de los grupos primarios a grupos cada vez más extensos (o por la transformación de la confianza personal en una "confianza sistémica"). Pero una teoría normativa no se acredita en las cuestiones de la psicología moral, sino que tiene que explicar la prioridad normativa de los deberes. En caso de conflicto entre una unión de sentimientos benevolentes, de un lado, y un mandamiento abstracto de la justicia, de otro, debe explicar por qué para los parientes debe ser racional que en aras de la solidaridad con extraños subordinen su lealtad para con aquellos por quienes sienten una confianza de persona a persona. Pero los sentimientos constituyen obviamente una base demasiado estrecha para la solidaridad entre los miembros de una entidad moral que se ha convertido en una comunidad confusa e inabarcable. ${ }^{31}$

30 HABERMAS, J. La inclusión del otro: estudios de teoría política, Barcelona: Paidós, 1999, p. 41. 


\subsection{El derecho tributario como positivación institucional de los deberes de solidaridad}

En ese contexto, el Derecho Tributario, constituye la institucionalización de los deberes morales de los ciudadanos, consistentes en el deber de contribuir al sustento de la institucionalidad jurídica, garantía ultima de la vida en común. Esos deberes no son los únicos que se institucionalizan jurídicamente, pero son -sin duda- los más importantes.

Podemos decir, entonces, que la tributación expresa en términos jurídico-formales el deber de solidaridad con la vida en común.

Dado que la trama moral de una sociedad no puede analizarse separando el momento de los derechos del momento de las cargas (responsabilidad), una auténtica justificación moral y política de los derechos debiera dirimirse argumentativamente junto con la argumentación en torno a las cargas que ello demandará. Y viceversa: la justificación de las cargas debiera justificarse en función de los derechos a cuya efectividad han de servir.

Consiguientemente, me parece oportuno destacar que el derecho tributario, y la administración tributaria en particular, son pieza clave en la comprensión de los deberes humanos, como parte ineludible de la moralidad básica de una sociedad.

31 Aclara Habermas, que EL PROBLEMA DE LA VINCULACIÓN EMOCIONAL CON EXTRAÑOS TAMPOCO SE PUEDE RESOLVER CON EL CAMBIO DE LA SIMPATÍA O LA CONFIANZA POR LA COMPASIÓN. AUN CUANDO NUESTRA CAPACIDAD DE SENTIR CON AQUELLAS CRIATURAS CAPACES DE SUFRIR VA MUCHO MÁS ALLÁ, SIN DUDA, QUE LOS SENTIMIENTOS POSITIVOS FRENTE A LAS PERSONAS ÚTILES, AGRADABLES Y DIGNAS DE CONFIANZA, LA COMPASIÓN NO CONSTITUYE UNA BASE SUFICIENTE PARA FUNDAMENTAR EL IGUAL RESPETO FRENTE A LOS OTROS TAMBIÉN Y JUSTAMENTE EN SU ALTERIDAD AL MARGEN DE LO QUE PODAMOS SENTIR. 


\subsection{La presupuestación republicana como clave de una política de derechos sustentable}

Bajo ese entendimiento, y articulando debidamente las exigencias liberales y republicanas que consagra nuestra constitución, la instancia privilegiada para justificar racionalmente el desarrollo de los derechos, debiera ser el proceso presupuestal, donde se adoptan los objetivos estratégicos y programáticos de la gestión de un gobierno.

Conferir derechos en función de reclamos sectoriales, o confiar en que los jueces resuelvan a demanda, es sin duda un camino de irracionalidad. No creo que debamos excluir estos mecanismos, ${ }^{32}$ pero me parece claro que no es la mejor manera de desarrollar los derechos de una ciudadanía solidaria, democrática, liberal y republicana.

\subsection{Posdata de actualidad: las lecciones de la crisis del mundo desarrollado}

En los últimos meses, la crisis económica europea ha sido noticia permanente. Mas allá de las consecuencias políticas y sociales que ya se perciben, me preocupa su impacto sobre la teoría de los derechos, por una razón que se me ocurre muy simple: Europa ha significado para nosotros el modelo a seguir en la construcción de una ciudadanía justa e igualitaria; ha sido el modelo de una institucionalidad basada en el permanente desarrollo de los derechos fundamentales y sus garantías institucionales, y consiguientemente, toda una cultura de los derechos y de la racionalidad política, que se refleja en la armoniosa construcción de sus catedrales teóricas que invaden nuestras aulas.

Sin embargo, la crisis económica, ha afectado - y no sabemos hasta dónde llegará- buena parte de los derechos consagrados por ese Estado de Bienestar.

32 Hace ya mucho tiempo contribuí a la fundamentación de la facultad de los magistrados como ordenadores de gastos, en: SARLO, Oscar. La justicia como ordenadora de gastos, en: CASSinelli mUÑOZ, H. et al.. Primer Coloquio Contencioso de Derecho Público. Responsabilidad del Estado y Jurisdicción, Montevideo: Editorial Universidad, 1993, pp. 105-117. 
Como respuesta racional a dicha crisis, los europeos empiezan a pensar que la clave está en "atar" los derechos al equilibrio fiscal. En este sentido va la reforma constitucional "express" sancionada en España ${ }^{33}$ y la iniciativa alemana de un rígido control de los presupuestos nacionales por los órganos centrales de la Unión Europea. ${ }^{34}$

Nuevamente, creo que se van imponiendo los prejuicios liberales sobre una concepción republicana del problema. La consagración de cláusulas automáticas en la constitución, sólo muestran la desconfianza hacia la política y hacia el Estado. Una solución republicana, debería implicar apostar a la política, pero a una política precisamente activa, participativa, sujeta a controles, y consciente de la íntima conexión entre derechos y deberes.

¿De qué podrán servir esas cláusulas automáticas en la constitución si el sistema político no es consciente de que su responsabilidad consiste en armonizar derechos y deberes ciudadanos, en lugar de actuar demagógicamente como un simple distribuidor de derechos?

La crisis europea es más inquietante, en cuanto paralelamente observamos el desarrollo exitoso de la experiencia de la República Popular China, un modelo situado en las antípodas, por estar fundado básicamente en los deberes, y en una ciudadanía con muy pocos derechos fundamentales.

Creo que los latinoamericanos, deberíamos reflexionar sobre el devenir de estos modelos, porque creo que ninguno de los dos constituye un modelo libre de riesgos.

33 La reforma constitucional fue aprobada en setiembre de 2011, y en lo sustancial, dispone que “Todas las Administraciones Públicas adecuarán sus actuaciones al principio de estabilidad presupuestaria." y que "El Estado y las Comunidades Autónomas no podrán incurrir en un déficit estructural que supere los márgenes establecidos, en su caso, por la Unión Europea para sus Estados Miembros. Una Ley Orgánica fijará el déficit estructural máximo permitido al Estado y a las Comunidades Autónomas, en relación con su producto interior bruto. Las Entidades Locales deberán presentar equilibrio presupuestario."

34 Las bases para la "unión presupuestal" impulsada por Alemania, se acaban de aprobar en la Cumbre Europea de Bruselas (8-12-2011), con la disidencia significativa de Gran Bretaña. 


\section{Bibliografia}

AAVV. El giro republicano. Bases conceptuales de déficit democrático de América Latina, Montevideo: Trilce, 2009.

ALEXY, Robert. Teoría de los Derechos Fundamentales, Madrid: Centro de Estudios Políticos y Constitucionales, 1986.

BAGGIO, Antonio. "La idea de 'fraternidad' entre dos Revoluciones: París 1789-Haití 1791. Pistas de Investigación para una comprensión de la fraternidad como categoría política”, en: BAGGIO, Antonio M. (comp.) El Principio Olvidado: La Fraternidad. En la Política y el Derecho, Buenos Aires: Ciudad Nueva, 54-57.

BASABE, Nere. "Derechos del Hombre" y "Deberes del Ciudadano" en la encrucijada: los lenguajes políticos de la Revolución Francesa y el Abad De Mably, en: Historia Constitucional, n. 12 [2011], pp. 45-98, http:// www.historiaconstitucional.com, accedido el 12-11-2011.

BAILYN, Bernard. The ldeological Origins of the American Revolution. Cambridge, Mass., 1967 [hay una edición posterior ampliada en Belknap Press of Harvard University Press; 1992]

BIASCO, Emilio. Introducción al estudio de los deberes constitucionales. El principio constitucional de solidaridad (http://www.ccee.edu.uy/ensenian/catderpu/material/deberes $\% 20$ constitucionales. PDF). Accedido: 12-11-2011.

CAETANO, Gerardo. La República Batllista, Montevideo: Banda Oriental, 2011.

CARRIÓ, Genaro. Nota Preliminar a: W.N. HOHFELD, Conceptos jurídicos fundamentales, Buenos Aires, CEAL, 1968.

CRUZ PARCERO, Juan Antonio. E1 lenguaje de los derechos: Ensayo para una teoría estructural de los derechos. Madrid: Trotta, 2007.

. El concepto de derecho subjetivo en la teoría contemporánea del derecho. México:

Fontamara, 1999.

EISSEN, Marc-Andre, La Convention Europeenne des Droits de l'Homme et les Obligations de l'indívidu: une mise a jour, en Rene Cassin. Amicorum Discipulorumque Liber, III, y The European Convention on Human Ríghts and the Duties of the Individual, en Acta Scandinavia Juris Gentium, Vol. 32. 1962, Fasc. 3-4.

GALLARDO, Javier. Diálogo en la república, en: Polis. Investigación y Análisis Sociopolítico y Psicosocial, Vol. 1, No. 1, 2005 , pags. 57-89.

. Las ideas republicanas en los orígenes de la democracia uruguaya, en: Araucaria: Revista

Iberoamericana de filosofía, política y humanidades, $N^{\circ}$ 9, 2003

GROS ESPIELL, Héctor. El constitucionalismo latinoamericano y la codificación en el siglo XIX, en: Anuario iberoamericano de justicia constitucional, Nº. 6, 2002, pags. 143-176.

La Convencion Americana y la Convencion Europea de Derechos. Analisis

Comparativo, Santiago: Editorial Jurídica de Chile, 1991.

FARELL, Martin D. El costo de los derechos, en Filosofía del Derecho y Economía, Buenos Aires: La Ley, 2006

de FRANCISCO, Andrés Ciudadanía y democracia: un enfoque republicano, Madrid: Los Libros de la Catarata, 2007.

GLENDON, M.A. Rights Talk. The Impoverishment Of Political Discourses, New York: The Free Press, 1991.

HABERMAS, Jürgen. La inclusión del otro: estudios de teoría política, Barcelona, Paidós, 1999.

Facticidad y Validez. Madrid: Trotta, 1998.

HOHFELD, W.N. Conceptos jurídicos fundamentales, México: Fontamara, 1991.

HOLMES, Stephen; SUNSTEIN, Cass R. El costo de los derechos. Por qué la libertad depende de los impuestos, Buenos Aires: Siglo XXI, 2011.

LAPORTA, Francisco. Sobre el concepto de derechos humanos. En Doxa, Núm. 4, (1987), p. 23.

LINDAHL, Lars. Position and change: a study in law and logic, Dordrecht-Holland; Boston-USA: D. Reidel Publishing Company, 1977.

LIPOVETSKY, Gilles. El crepúsculo del deber. La ética indolora de los nuevos tiempos democráticos, Barcelona: Anagrama, 5 ${ }^{\text {a }} 2000$. 
LYONS, D. The Correlativity of Rights and Duties: Noüs 4/1 (1979), pp. 45-55.

NIEMI, Matti. Hohfeld y el análisis de los Derechos. México: Fontamara, 1996.

NINO, Carlos S. La constitución de la democracia deliberativa, Barcelona: Gedisa, 1996.

O’NEILL, Onora. Towards Justice and Virtue, Cambridge: Cambridge University Press, 1996.

Constructions of reason: explorations of Kant's practical philosophy, Cambridge:

Cambridge University Press, 1989.

PETTIT, Philip. Republicanismo, Barcelona: Paidós, 1999.

POCOCK, J. G. A., The Machiavellian Moment: Florentine Political Thought and the Atlantic Republican Tradition. Princeton, N.J.: Princeton University Press, 1975.

RIVERO, Ángel. Republicanismo y neo-republicanismo, en revista ISEGORIA, no 33, (2005) pp. $5 \cdot 17$

ROSS, Alf. Sobre el Derecho y la Justicia, Buenos Aires: Eudeba, 1963.

SARLO, Oscar. Derechos, Deberes y Garantías implícitos en la Constitución Uruguaya. Un análisis de filosofía política y epistemología del derecho, en: VÁZQUEZ, Cristina (comp.). Estudios Jurídicos en Homenaje al Prof. Juan Pablo Cajarville Peluffo, Montevideo: FCU, 2011, pp. 1069-1099.

Sobre la noción de responsabilidad en la teoría del derecho y dogmática jurídica, en:

Ruptura. Una revista Interdisciplinaria de Análisis Jurídico, Montevideo, 2011, No 1, pp. 41-54.

La justicia como ordenadora de gastos, en: CASSINELLI MUÑOZ, H. et al.. Primer

Coloquio Contencioso de Derecho Público. Responsabilidad del Estado y Jurisdicción, Montevideo: Editorial Universidad, 1993, pp. 105-117.

TAYLOR, Ch. Philosophy and the human sciences, U.S.: Cambridge University Press, 1985.

WOOD, Gordon S. The Creation of the American Republic, 1776-1787, Chapel Hill: University of North Carolina Press, 1969. 